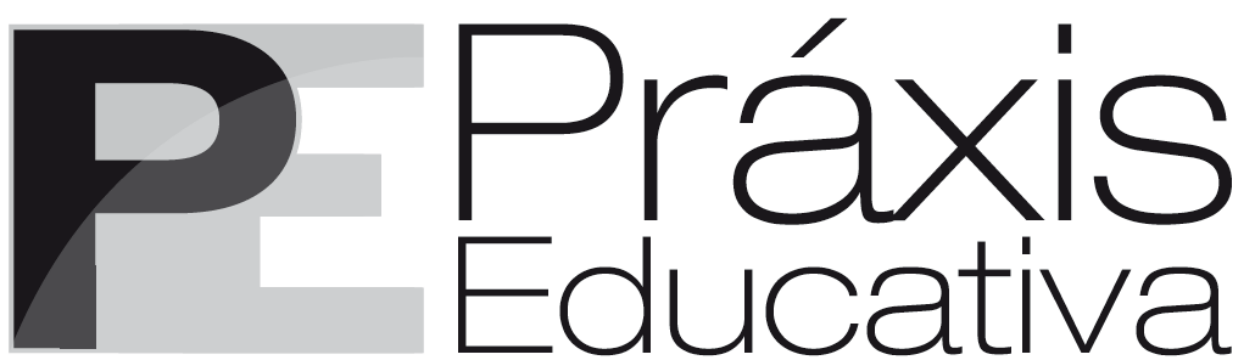

ISSN 1809-4309 (Versão online)

DOI: 10.5212/PraxEduc.v.11i2.0011

\title{
Formação de professores e prática pedagógica: uma análise sobre a natureza dos saberes docentes ${ }^{*}$
}

\section{Teacher education and pedagogical practice: analysis on the nature of teacher knowledge}

\section{Formación de maestros y la práctica pedagógica: un análisis sobre la naturaleza de los saberes docentes}

\author{
Camila Macenhan ${ }^{* *}$ \\ Susana Soares Tozetto ${ }^{* * *}$ \\ Celia Finck Brandt ${ }^{* * * *}$
}

\begin{abstract}
Resumo: O presente texto tem como objeto o saber docente, com o objetivo central de desvelar, por meio de interpretações inferenciais, o saber do professor da Educação Infantil diante da prática pedagógica. A investigação envolveu quatro (4) professoras da Educação Infantil, utilizou as observações e as entrevistas para a coleta dos dados e contou com a Análise de Conteúdo (BARDIN, 2011) para o tratamento das informações empíricas. Os fundamentos utilizados na pesquisa envolvem estudos de Tardif (2002), Gauthier et al. (2006) e Gimeno Sacristán (1999). Os resultados mostram que os saberes docentes originam tanto dos cursos de formação de professores quanto de suas experiências pessoais e profissionais. Os momentos citados fornecem elementos que constituem fontes de aprendizagem dos saberes que, por sua vez, passam por processos de desenvolvimento e são mobilizados na prática pedagógica de modo a influenciar e receber interferências dessa prática.

Palavras-chave: Saberes docentes. Formação de professores. Prática pedagógica.
\end{abstract}

\begin{abstract}
This paper deals with teacher knowledge, with the aim of unveiling, through inferential interpretations, the teacher knowledge of the early childhood teacher when facing pedagogical practice. The investigation involved four early childhood education teachers, employed observations and interviews as data collection and relied on content analysis (BARDIN, 2011) to treat the empirical information. The foundations used in the research involve studies of Tardif (2002), Gauthier et al. (2006) and Gimeno Sacristán (1999). The results show that teacher knowledge originates both from teacher education courses and their personal and professional experiences. The aforementioned moments provide elements that constitute knowledge learning sources that, in turn, go through development processes and are mobilized during teaching practice so as to influence their practice and receive interference from it.
\end{abstract}

\footnotetext{
* O presente artigo baseia-se na Dissertação de Mestrado de Camila Macenhan. Resultados parciais da pesquisa foram apresentados no XII Congresso Nacional de Educação - Educere.

${ }^{* *}$ Doutoranda em Educação. PPGE-UEPG. E-mail: <camila.macenhan@hotmail.com>.

*** Professora da Universidade Estadual de Ponta Grossa (UEPG). E-mail: <tozettosusana@hotmail.com>.

**** Professora da Universidade Estadual de Ponta Grossa (UEPG). E-mail: <brandt@bighost.com.br>.
}

Práxis Educativa, Ponta Grossa, v. 11, n. 2, p. 505-525, maio/ago. 2016 Disponível em: < http://www.revistas2.uepg.br/index.php/praxiseducativa > 
Keywords: Teacher knowledge. Teacher education. Pedagogical practice.

Resumen: El presente texto trata del saber docente, con el objetivo central de revelar, a través de interpretaciones inferenciales, la naturaleza del saber docente del maestro de Educación Infantil ante la práctica pedagógica. En la investigación participaron cuatro maestras de Educación Infantil, se utilizaron las observaciones y entrevistas para la recogida de datos y se contó con el Análisis de Contenido (BARDIN, 2011) para el tratamiento de las informaciones empíricas. Los fundamentos utilizados en la investigación incluyen estudios de Tardif (2002), Gauthier et al. (2006) y Gimeno Sacristán (1999). Los resultados muestran que los saberes docentes se originan tanto de los cursos de formación de maestros, como de sus experiencias personales y profesionales. Los momentos citados proporcionan elementos que constituyen fuentes de aprendizaje de conocimientos que, a su vez, pasan por procesos de desarrollo y son movilizados en la práctica pedagógica con el fin de influir y recibir interferencias de esta práctica.

Palabras clave: Saberes docentes. Formación de maestros. Práctica pedagógica.

\section{A prática pedagógica e o processo de constituição dos saberes docentes na Educação Infantil}

A prática exerce influência na constituição dos saberes docentes desde a formação inicial dos professores quando eles têm acesso às escolas por meio dos estágios. De acordo com Vaillant e Marcelo (2012, p. 75): “As práticas de ensino seguem sendo o elemento mais valorizado, tanto pelos docentes em formação como em exercício, com relação aos diferentes componentes do currículo formativo". Depois de formados, a prática responsabilizar-se-á por demonstrar aos sujeitos as necessidades de aprimoramento constante para o exercício da docência.

A proposta do presente trabalho investigativo levou em consideração o fato de que a prática pedagógica caracteriza uma fonte inesgotável de saberes, no entanto: "Os saberes da ação pedagógica legitimados pelas pesquisas são atualmente o tipo de saber menos desenvolvido no reservatório de saberes do professor, e também, paradoxalmente, o mais necessário à profissionalização do ensino" (GAUTHIER et al., 2006, p. 34). Ao discorrer sobre as consequências da falta de um saber da ação pedagógica válido, Gauthier et al. (2006) consideram que uma profissão não se caracteriza na ausência da competência com a demarcação de conhecimentos próprios e validados pelo grupo.

Nesse sentido, há a necessidade de os saberes serem formalizados à medida que legitimados pela pesquisa e pela prática dos professores. Com isso, a relação teoria e prática ficaria melhor situada, porque haveria um diálogo mais significativo entre universidade e escola, ou seja, entre as bases teóricas e as práticas. A fim de ilustrar essa condição, Gauthier et al. (2006, p. 35) delineiam o seguinte panorama: "[...] a formação inicial, recebida na Universidade, refletiria melhor a prática no meio escolar, e o saber do próprio professor, difundido no seio da Universidade, acharia aí um reconhecimento de sua pertinência". Percebemos que, ao estabelecer saberes formalizados, a profissão adquire reconhecimento social, mas, de acordo com os autores, tal condição não ocorre de modo automático e imediato, pois necessita do reconhecimento pelos pares e pela sociedade.

Ao referirmo-nos à prática pedagógica, acreditamos ser importante salientar que a presente pesquisa buscou a análise das situações do trabalho docente. Defendemos a importância de considerar o estudo da prática pedagógica diante da questão dos saberes docentes pelo caráter de imprevisibilidade que a docência possui e, ao mesmo tempo, demonstra uma estrutura com elementos estáveis. As situações distintas presentes na atividade do dia-a-dia em sala de aula

Práxis Educativa, Ponta Grossa, v. 11, n. 2, p. 505-525, maio/ago. 2016 Disponível em: <http://www.revistas2.uepg.br/index.php/praxiseducativa $>$ 
demandam opções dos professores e a ciência de que a condição heterogênea dos alunos poderá proporcionar o êxito ou o fracasso das propostas, dependendo das ações docentes também. As contradições, da forma como descrevem Gauthier et al. (2006), fazem parte do cotidiano docente, ou seja, as incertezas compõem esse quadro.

A prática é conceituada por Gimeno Sacristán (1999, p. 73) como a cultura acumulada sobre as ações. Desse modo, é ao mesmo tempo fonte das ações e nutre-se delas: "A prática é a cristalização coletiva da experiência histórica das ações, é o resultado da consolidação de padrões de ação sedimentados em tradições e formas visíveis de desenvolver a atividade". Assim, a prática proporciona as ações e também recebe interferências destas, sendo a prática institucionalizada com o babitus.

A partir da definição de prática de modo geral, amparamo-nos em Gimeno Sacristán (1999) para definir a prática educativa como algo mais que a expressão do ofício dos professores, como uma cultura compartilhada pelos profissionais da educação. De acordo com o autor mencionado, a gênese da prática educativa está em outras práticas capazes de interagir com o sistema escolar, mantendo relação com os demais âmbitos da sociedade, por exemplo, o político e o econômico. Gimeno Sacristán (1999) ainda apresenta o conceito de prática pedagógica como aquela que acontece nas salas de aula e não pode ser tomada de modo isolado ou em uma perspectiva de prática cultural autônoma.

Quando nos propomos analisar a prática pedagógica, é indispensável atentarmos para as situações que a compõem, as quais poderão envolver-se em uma rotina massificante proveniente da cotidianidade. Por tal motivo, as situações podem passar despercebidas devido à ausência de sentido explícito. Por isso, a reflexão e a contestação são cruciais para vencermos o julgamento rotineiro ausente de sentido, assim como para a percepção de que o real, referente ao dia-a-dia, não pode ser imperceptível.

A preocupação com os detalhes diante de cada situação específica e em relação com o todo é importante na análise da prática pedagógica, pois esta pode até fazer parte da cotidianidade. Contudo, o discurso presente no espaço do cotidiano não é simplesmente inofensivo ou inocente, porque tem ideologias implícitas (HELLER, 1985). Cientes de que a prática do professor é um dos eixos centrais para a compreensão da constituição dos saberes docentes, necessitamos considerá-la durante todo o processo de formação.

Com a atribuição de sentido à prática da profissão, o trabalho docente ganha uma perspectiva ampla e, por isso, podemos visualizar a influência da instituição escolar na constituição dos saberes. Logo, a escola interfere nos saberes do professor, mas ele próprio elabora-os, porque ele não os adquire pelo processo de transmissão. Assim, explicitamos que nosso posicionamento não envolve a atitude pragmática em busca da transmissão de modelos prévios de como deve ser um bom professor, mas o estudo de elementos que interferem na natureza do saber docente. Assim sendo, consideramos que o conjunto de experiências do professor na qualidade de aluno e suas atitudes cotidianas repercutirão na forma como ele constituirá seus saberes. Toda a caminhada referente à formação profissional e aos princípios organizacionais da própria escola também terão consequências nas ações do professor. Assim, ressignificamos constantemente nossos saberes, mesmo porque há um paradoxo quanto aos professores hoje: "[...] são estrangeiros em um ambiente bastante familiar, pois no ambiente escolar estiveram até então somente como alunos e não como professores" (SILVA, 2009, p. 41). Conhecemos o ambiente da escola e, concomitantemente, o desconhecemos, em razão de que a responsabilidade pelo ensino advém da condição em que nos tornamos professores, não da situação estudantil.

Práxis Educativa, Ponta Grossa, v. 11, n. 2, p. 505-525, maio/ago. 2016 Disponível em: <http://www.revistas2.uepg.br/index.php/praxiseducativa > 
Quando o professor analisa a própria prática faz com que ele visualize o seu trabalho em uma dimensão mais ampla e reflexiva. A reflexão crítica pautada no conhecimento científico possibilita a emancipação do professor perante as atividades desenvolvidas e a mecanização cede espaço para a razão, a consciência das condições da docência e a capacidade de transformações. Ao valorizar a prática pedagógica, o processo de análise deixa de pertencer somente ao âmbito das ideias e passa para a situação concreta. Assim, Tardif (2002) afirma:

Nesse sentido, a prática pode ser vista como um processo de aprendizagem através do
qual os professores retraduzem sua formação e a adaptam à profissão, eliminando o
que lhes parece inutilmente abstrato ou sem relações com a realidade vivida e
conservando o que pode servir-lhes de uma maneira ou de outra. (TARDIF, 2002, p.
53).

O processo de aprendizagem da docência traz o papel da prática na constituição dos saberes e fica-nos explícita a necessidade para o professor de repensar as ações e atribuir juízos de valor ao aprendizado proveniente da formação e das situações cotidianas. Para Gimeno Sacristán (1999, p. 74): "A prática é fonte da ação, e os caminhos gerados por esta, dentro daquela, podem enriquecê-la e redirecioná-la, condicionando o seu desenvolvimento histórico". A partir disso, percebemos que a prática carrega uma história, e o autor a concebe como cultura objetiva acumulada, no entanto, ativa e não inerte.

Da mesma forma, Gimeno Sacristán (1999) salienta os reflexos da cultura geral na subcultura, relativa às práticas educativas, porque o agente pedagógico, ou seja, o professor constitui-se dentro de ambas as culturas. Nessa condição, a prática docente advém da prática pedagógica e esta, por sua vez, tem maior especificidade que a prática educativa, mas as três recebem e agregam elementos à cultura geral. A relação entre os componentes da ação pessoal (saber-fazer, conhecimento pessoal e motivos pessoais) com a cultura expressa na prática pedagógica é contínua.

A prática dos professores, portanto, abrange conjuntos de saberes e ela não os produz por completos, pois a cultura geral e a subcultura estão em constante relação, e a prática docente também possui características já institucionalizadas. Nesse sentido, muitas vezes os professores mantêm o papel de transmissores e não de produtores dos direcionamentos de seu trabalho; entretanto, deveriam participar da constituição dos saberes específicos da docência de modo mais intenso, a ponto de garantir a originalidade deles e contribuir para o processo de profissionalização. A função docente, mesmo definindo-se com a relação entre os saberes, parece incapaz de determinar um saber que seria produzido e controlado pelos professores. A relação dos professores com os saberes é de exterioridade, porque eles não produzem um saber para impor como instância de legitimação social de sua função e como espaço de verdade de sua prática com a objetivação das experiências (TARDIF, 2002).

A prática da profissão possibilita ao professor objetivar os saberes da experiência. A partir do contato real com o espaço da aula, Silva (2009) destaca a transformação das incertezas, das angústias e das dúvidas do professor ao transmitir conteúdos, regras e valores em algo natural e carregado de características do profissional. É por meio da prática da profissão que o professor participa das situações inéditas relacionadas ao exercício de sua profissão. Com o processo de reflexão crítica, o professor consegue atribuir sentido ao curso de formação inicial, continuada e em serviço e ainda a sua vivência profissional no cotidiano da sala de aula. Conforme Silva (2009) traz-nos, a reflexão crítica oportuniza a análise de situações singulares a partir de teorias abrangentes.

Da mesma forma, Therrien e Loiola (2001) demonstram que o eixo fundante da formação dos professores é o saber advindo da compreensão sobre a práxis e assim relativo ao

Práxis Educativa, Ponta Grossa, v. 11, n. 2, p. 505-525, maio/ago. 2016 Disponível em: <http://www.revistas2.uepg.br/index.php/praxiseducativa > 
saber da experiência. Os autores citados analisam a natureza do saber professoral a partir da lógica socioepistemológica, na perspectiva da ação comunicativa, com destaque para aspectos da experiência social e considerando a perspectiva reflexiva dos sujeitos, além da necessidade de o professor ser visto como pesquisador de sua prática. A atuação docente é colocada como um elemento que possui grande significado para compreendermos o processo de saber-ensinar.

As questões sobre a constituição do saber docente, apontadas por Therrien e Loiola (2001), requerem estudos a respeito da prática. Afirmamos tal condição quando os autores aludidos defendem que:

[...] a tradição generalista da formação pedagógica incentivou uma prática de pesquisa e formação científica muito ampla e dispersa, deixando de lado os olhares mais precisos e pontuais sobre os saberes (conhecimentos, hábitos, competências) efetivamente presentes no chão da sala de aula e nas intervenções educacionais desenvolvidas em outros espaços. (THERRIEN; LOIOLA, 2001, p. 147).

Nessa direção, Therrien e Loiola (2001) propõem a necessidade de análises em relação à formação dos professores e a constituição dos saberes a partir de estudos dirigidos ao trabalho docente, situado em contextos reais da prática. Os autores destacam também a importância de abordagens teórico-metodológicas preocupadas com a identificação e a compreensão das especificidades dos sujeitos de tal prática.

Sobre o professor aprender ao longo do contexto real da prática e por meio da experiência, Gauthier et al. (2006, p. 32) afirmam: "De fato, aprender através de suas próprias experiências significa viver um momento particular, momento esse diferente de tudo o que se encontra habitualmente, sendo registrado como tal em nosso repertório de saberes". Aprender ao longo das experiências, com a associação entre os conceitos das ciências da educação e o que o professor vivência em sala de aula tem grande significado no repertório de conhecimentos específicos ao ensino, ou seja, na constituição do saber professoral.

\section{A relação entre a formação docente na perspectiva do desenvolvimento profissional e o processo de constituição do saber professoral}

A terminologia "formação", segundo nosso entendimento, supõe prazos. Aqui não nos referimos apenas aos prazos curtos e resultados imediatistas, porque o profissional percorre uma carreira ao exercer a docência e as transformações em suas posturas também acontecem. Compreendemos, portanto, o processo de formação docente como contínuo e amparamo-nos na definição de desenvolvimento profissional de acordo com Vaillant e Marcelo (2012). O desenvolvimento profissional docente tem o sentido de atitude permanentemente questionadora em busca da melhoria escolar, de continuidade, de evolução a fim da superação à justaposição entre formação inicial e aperfeiçoamento dos professores (VAILLANT; MARCELO, 2012).

As oportunidades de aprendizagem são o centro do desenvolvimento profissional docente, a partir das interações sociais e dos momentos da carreira que se encontra o professor: "O contexto espacial no qual se desenvolve a atividade docente influi, mas há uma dimensão temporal ou biográfica que também exerce sua influência na atitude que se adota ante o desenvolvimento profissional" (VAILLANT; MARCELO, 2012, p. 170). Compreendemos que as condições de trabalho, no caso o ambiente em que acontecem as ações do professor, compondo o contexto espacial, e a fase da carreira vivenciada por eles, ao delinear a dimensão temporal, interferem no desenvolvimento profissional docente.

Práxis Educativa, Ponta Grossa, v. 11, n. 2, p. 505-525, maio/ago. 2016 Disponível em: <http://www.revistas2.uepg.br/index.php/praxiseducativa> 
O desenvolvimento profissional docente, problematizado na obra de Vaillant e Marcelo (2012), surge como uma proposta para repensarmos a formação dos profissionais atuantes na escola. De acordo com os autores,

[...] o desenvolvimento profissional docente tem a ver com a aprendizagem; remete ao trabalho; trata de um trajeto; inclui oportunidades ilimitadas para melhorar a prática; relaciona-se com a formação dos docentes; e opera sobre as pessoas, não sobre os programas. (VAILLANT; MARCELO, 2012, p. 169).

Fica-nos perceptível a preocupação central do desenvolvimento profissional com o docente e não com os programas dedicados a ele. Dessa forma, os referidos autores expõem a relevância do contexto espacial e temporal para a aprendizagem dos professores, pois as condições de trabalho podem ou não auxiliar no desenvolvimento profissional. Além desse contexto, há o aspecto do momento da carreira em que o docente se encontra e seus centros de interesse, compondo a dimensão temporal ou biográfica aludida.

A formação inicial do professor compõe parte do desenvolvimento profissional. Vaillant e Marcelo (2012) identificam o período inicial de formação do professor como primeiro ponto de acesso ao desenvolvimento profissional contínuo. Um programa, preocupado com a formação profissional ampla, oportuniza caminhos para a pesquisa e mostra que, para aprender a ensinar, não há uma receita ou um momento de finalização na formação para o exercício da prática em sala. Nessa perspectiva, aprender a ensinar depende não apenas da formação inicial ou continuada de modo dissociado, mas da formação dos professores a partir da concepção de desenvolvimento profissional docente.

Ao tratarmos de desenvolvimento profissional, certamente a formação inicial dos professores é uma das peças chaves desse processo. Com alicerces consistentes, o professor percebe a necessidade da construção contínua de conhecimentos profissionais. Ao trazerem suas considerações sobre a formação inicial, Vaillant e Marcelo (2012) defendem o momento de inserção profissional como extremamente pertinente para os futuros professores. Segundo as constatações dos autores mencionados, há variações de um país para outro no período de inserção: "Não é um salto no vazio entre a formação inicial e a formação contínua, mas sim tem um caráter distintivo e determinante para conseguir um desenvolvimento profissional coerente e evolutivo" (VAILLANT; MARCELO, 2012, p. 125). A inserção é uma proposta para compor o projeto maior voltado ao desenvolvimento profissional dos docentes.

A articulação entre as situações de formação com as práticas de sala de aula é essencial para propostas eficazes de desenvolvimento profissional. Vaillant e Marcelo (2012) corroboram a síntese anterior no seguinte sentido:

Diferentemente das práticas tradicionais de formação, que não relacionam as situações de formação com as práticas de sala de aula, as experiências mais eficazes para o desenvolvimento profissional são aquelas que estão baseadas na escola e que se inscrevem dentro das atividades cotidianas dos professores. (VAILLANT; MARCELO, 2012, p. 196).

O elo entre formação e prática em sala de aula possibilita a ressignificação pelo professor de seus saberes. Elencamos a denominação desenvolvimento profissional para trabalharmos ao longo deste texto pelo motivo de que a concepção em questão considera o movimento constante de ir e vir na constituição dos saberes docentes. Segundo Nóvoa (1992, p. 27): “A formação pode estimular o desenvolvimento profissional dos professores, no quadro de uma autonomia contextualizada da profissão docente". Os processos de formação capazes de instigar os professores à reflexão demonstram preocupação com a preparação de sujeitos protagonistas,

Práxis Educativa, Ponta Grossa, v. 11, n. 2, p. 505-525, maio/ago. 2016 Disponível em: <http://www.revistas2.uepg.br/index.php/praxiseducativa $>$ 
Formação de professores e prática pedagógica: uma análise sobre a natureza dos saberes docentes

responsáveis pelo seu próprio desenvolvimento profissional e para a constituição dos saberes docentes.

Sobre a formação docente e a mobilização de saberes, Gauthier et al. (2006) ressaltam que o conhecimento específico ${ }^{3}$ de ensinar, adquirido nos processos formativos e em constante relação teórico prática, diferencia o professor dos demais profissionais. Ao defenderem essa proposição, os autores evidenciam que:

De fato, na ausência de um saber da ação pedagógica válido, o professor, para fundamentar seus gestos, continuará recorrendo à experiência, à tradição, ao bom senso, em suma, continuará usando saberes que não somente podem comportar limitações importantes, mas também não o distinguem em nada, ou em quase nada, do cidadão comum. (GAUTHIER et al., 2006, p. 34).

A importância da formação docente como uma das formas de legitimação dos saberes do professor fica evidente e com tal processo é possível a aceitação, por parte da população como um todo, de saberes e de práticas constituídas pela categoria, sendo uma condição para o processo de profissionalização. Gauthier et al. (2006, p. 34) colocam que, "[...] para profissionalizar o ensino é essencial identificar saberes da ação pedagógica válidos e levar os outros atores sociais a aceitar a pertinência desses saberes". Ao longo das considerações, os autores ainda demonstram a importância da relação entre as pesquisas sobre a prática docente com os cursos de formação inicial como forma de reconhecer o valor do saber originado na ação pedagógica.

O vínculo entre a formação e a realidade das escolas é um dos itens centrais para repensarmos a situação da educação. O fracasso nas práticas de sala de aula, as desistências e as frustrações com a carreira docente provêm, muitas vezes, da inexperiência dos professores recém-formados por meio de programas despreocupados com a relação entre o aporte teórico trabalhado com os acadêmicos e o espaço escolar carregado de anseios. Para Nóvoa (1992), a formação do professor permeia-se pelo trabalho de reflexibilidade crítica sobre as práticas e pela (re)construção permanente de uma identidade pessoal; logo, a simples acumulação de cursos, conhecimentos ou técnicas não determina a formação em sua amplitude.

Sobre a dimensão ampla da formação de professores e as lacunas que encontramos ao longo dos processos formativos, Vaillant e Marcelo (2012) salientam questões referentes a paradoxos na relação entre formação de professores e prática em sala. De acordo com os autores mencionados, para o exercício profissional contribuir na constituição dos saberes, o próprio profissional é o responsável por construir a ponte entre as bases teóricas e o cotidiano da sua sala de aula, porém as práticas profissionais apresentam limitações.

Vaillant e Marcelo (2012) analisam como primeira lacuna presente na formação docente a familiaridade precoce com a prática, a partir da qual os futuros profissionais já observaram inúmeras situações da atuação docente quando eram alunos e podem até julgar como desnecessária uma formação acadêmica complementar. As crenças arraigadas dificultam uma ação embasada em princípios comprovados e remetem a uma ação alicerçada no empirismo.

Outra lacuna pertencente à relação entre formação e atuação, descrita nos estudos de Vaillant e Marcelo (2012), refere-se à dissociação entre a instituição de formação e os conhecimentos profissionais. Os autores utilizam a denominação para a seguinte lacuna como a

\footnotetext{
${ }^{3}$ Quanto à especificidade da docência, Gauthier et al. (2006, p. 77) afirmam: “Em situações que exigem a sua ação, o profissional utiliza um saber específico que o distingue das outras ocupações. Por esse motivo, a identificação e a validação de um repertório de conhecimentos específicos ao ensino contribuiria, com certeza, para definir o status profissional dos professores".
}

Práxis Educativa, Ponta Grossa, v. 11, n. 2, p. 505-525, maio/ago. 2016 Disponível em: <http://www.revistas2.uepg.br/index.php/praxiseducativa > 
dos dois mundos e discorrem sobre o fato de que há a possibilidade de os estudantes para a docência identificarem-se fortemente com a realidade das escolas, ocasionando a repulsão aos conhecimentos que fundamentam a prática.

Como terceira limitação que pode estar presente na relação teórico prática entre cursos de formação e exercício profissional, Vaillant e Marcelo (2012) analisam as divergências entre os propósitos da instituição de formação e das escolas. Assim, o período de estágio, se bem fundamentado, proporciona a vivência pura das atividades da escola e não um simples momento de exercitar. Muitas vezes, não presenciamos a realidade pura das escolas pelos estágios devido à incompreensão sobre a pertinência do momento para o futuro professor, a ponto de a instituição escolar demonstrar práticas artificiais.

Uma grande vantagem dos processos formativos que se preocupam com os alicerces teóricos e também com a prática docente é a de que, além de mobilizar o profissional para atitudes reflexivas, a inserção do professor em seu ambiente de trabalho faz com que ele se depare com novas situações. Tais pontos aparecem nas discussões de Silva (2009), mas, por outro lado, as lacunas da prática também compõem sua apreciação e, por isso, a superação destas depende da compreensão proveniente dos estudos teóricos do profissional.

\begin{abstract}
Nesse sentido, as experiências cotidianas e a reflexão-na-ação fazem [com] que esse profissional (o professor) ultrapasse as teorias científicas disponíveis, valendo-se de sua experiência pessoal, de seus valores e de seus sentimentos para solucionar qualquer conflito. Essa experiência pessoal, bem como os valores e sentimentos, é também caracterizada pela contemporaneidade histórica: para o bem e para o mal. É preciso dizer. (SILVA, 2009, p. 30).
\end{abstract}

A prática como um componente dos saberes docentes na Educação Infantil e na perspectiva do desenvolvimento profissional demanda, ao mesmo tempo, a dimensão teórica associada. Nos casos inspiradores de inserção à docência, a parceria entre escola e universidade oportuniza tanto o contato do futuro profissional com a prática da sala de aula, como a relação com o conhecimento sistematizado nos ambientes acadêmicos.

\title{
Os saberes docentes na perspectiva de Tardif (2002) e Gauthier et al. (2006)
}

O professor não tem mais a função de transmissor. Hoje, ele assume a posição na qual é o mediador da aprendizagem, portanto necessita de elementos além do domínio dos conteúdos. A preocupação com os saberes do professor advém da visualização do papel desse profissional na escola como autor. Nessa direção, identificamos abordagens distintas para trabalhar com a configuração dos saberes docentes. Assim, com a intenção de desenvolver a ideia sobre quais são as fontes de conhecimento base para a docência, apoiamo-nos em Tardif (2002) e Gauthier et al. (2006). As perspectivas dos autores aludidos convergem em determinados pontos e em outros apresentam peculiaridades.

Para Tardif (2002), os saberes profissionais dos professores podem ser caracterizados como temporais, plurais e heterogêneos, personalizados e situados, carregados de marcas do ser humano devido a esse ser o objeto do trabalho docente. Os saberes possuem estas dimensões porque a sensibilidade e as emoções perpassam o trabalho do professor e, conforme aponta Tardif (2002), o professor, ao interagir com seus alunos, também conhece seus próprios sentimentos ao longo do desenvolvimento das aulas.

A partir dessa especificidade da docência, Tardif (2002) destaca que a realidade cotidiana da profissão demanda uma formação para os professores além daquela associada ao domínio das

Práxis Educativa, Ponta Grossa, v. 11, n. 2, p. 505-525, maio/ago. 2016 Disponível em: <http://www.revistas2.uepg.br/index.php/praxiseducativa > 
técnicas. A valorização do ambiente escolar e do papel do professor é fundamental à formação docente preocupada com a transformação das instituições de ensino, por meio de atitudes críticas. Tardif (2002) busca situar o saber do professor na interface entre o individual e o social, entre o ator e o sistema. $\mathrm{O}$ autor referenciado atribui uma natureza social e, ao mesmo tempo, individual ao saber docente; por isso cita os fios condutores da sua concepção de modo geral.

Dentre os seis fios condutores destacados na análise de Tardif (2002), a relação do saber do professor com o próprio trabalho nas escolas e na sala de aula aparece; destarte, o saber apresenta-se mediado pelo trabalho, a serviço deste. Em suas palavras, "[...] embora os professores utilizem diferentes saberes, essa utilização se dá em função do seu trabalho e das situações, condicionamentos e recursos ligados a esse trabalho" (TARDIF, 2002, p. 17). As situações cotidianas mobilizam nossos saberes, proporcionam o pensar e o repensar sobre as ações; no entanto, esses processos reflexivos não acontecem na ausência do saber específico da docência.

Frente à pluralidade de saberes presentes nas práticas e nos processos formativos dos professores, do mesmo modo que Tardif (2002) nos aponta a diversidade como segundo fio condutor da sua perspectiva, ressaltamos a heterogeneidade do saber docente. O saber-fazer do professor é diferente, porque envolve a mobilização de múltiplas fontes como as etapas da formação, os conhecimentos prévios ao ingresso na profissão e as experiências ao longo do exercício da docência. Por conseguinte, os saberes podem ser caracterizados como temporais; condição atrelada tanto à história escolar ou familiar dos professores como a sua carreira. Aqui está o terceiro fio condutor considerado pelo autor em questão.

A experiência de trabalho do professor, sendo o quarto fio condutor, apresenta-se como fundamento do seu saber. O exercício profissional abrange as experiências de trabalho e, pela reflexividade do professor, a relação entre o conhecimento apreendido até então com o saberfazer. A prática profissional aparece como um produto da mobilização de saberes adaptados e transformados pelo e para o trabalho (TARDIF, 2002).

A interação entre os sujeitos, como citamos, é uma das características da docência. De tal modo, o próximo fio condutor, segundo a perspectiva de Tardif (2002), refere-se aos saberes humanos a respeito de seres humanos. A relação do professor com o seu objeto de trabalho exerce influência nos saberes do profissional em questão. Como percebemos: "A questão do saber está ligada, assim, à dos poderes e regras mobilizados pelos atores sociais na interação concreta" (TARDIF, 2002, p. 22). Professores e alunos são atores, produzem novos saberes, da mesma forma, ressignificam os sentidos dos saberes presentes até o momento.

A formação de professores é o sexto fio condutor da análise e decorrente dos demais fios citados. O ato de repensar o viés da formação envolve a articulação com os saberes dos professores e as realidades específicas de seu trabalho cotidiano. Os conhecimentos disciplinares até agora dominaram a formação docente, no entanto, sem nenhuma conexão com a ação profissional, somente para serem aplicados na prática por meio dos estágios ou atividades do gênero, com base em uma visão linear. O conhecimento do trabalho dos professores e os saberes cotidianos permitem a renovação da concepção sobre o que seja formar o profissional, sua identidade e o papel que possui na sociedade (TARDIF, 2002).

A origem social e os modos de integração dos sujeitos no magistério abrangem o saber dos professores apontado por Tardif (2002). Dessa forma, a composição de tal saber envolve tipologias com procedências distintas, dentre estas: os saberes da formação profissional, os saberes disciplinares, os saberes curriculares e os saberes experienciais.

Práxis Educativa, Ponta Grossa, v. 11, n. 2, p. 505-525, maio/ago. 2016 Disponível em: <http://www.revistas2.uepg.br/index.php/praxiseducativa> 
Da mesma forma, o modo como o professor constitui e mobiliza seus saberes também é objeto dos estudos de Gauthier et al. (2006), e as conclusões apontam para a existência de uma espécie de reservatório, por meio do qual o professor ampara-se quando busca respostas específicas para seu trabalho. O saber entra como elemento importante para a profissionalização docente e pode ser abordado como traço característico maior de uma profissão ou como uma poderosa arma ideológica.

Indiferentemente das situações que abordam o saber, este é central em todo o processo de profissionalização de uma ocupação (GAUTHIER et al., 2006). Nessa perspectiva, um repertório de saberes próprios representa um conjunto de conhecimentos bem demarcado e desenvolvido pela profissão, a ponto de dar maior status à docência ao afastá-la do senso comum, envolvendo esse reservatório de saberes mencionado por Gauthier et al. (2006): o saber disciplinar, o saber curricular, o saber das ciências da educação, o saber da tradição pedagógica, o saber experiencial e o saber da ação pedagógica.

Quando o professor apresenta um saber específico, ele denota certo controle sobre a docência, favorecendo a profissionalização, porque demonstra aspectos capazes de distingui-la das demais ocupações, logo: "[...] a identificação e a validação de um repertório de conhecimentos específicos ao ensino contribuiria, com certeza, para definir o status profissional dos professores" (GAUTHIER et al., 2006, p. 77). Nessa perspectiva, o estabelecimento de um conjunto de saberes representa uma das etapas a caminho da profissionalização docente, e um repertório de conhecimentos específicos ao ensino refere-se ao corpus de saberes que necessitará tanto do reconhecimento científico quanto do social.

Para a composição do saber docente específico, a prática pedagógica é uma fonte para o processo em questão e que necessita ser validado. No entanto: "Os saberes da ação pedagógica legitimados pelas pesquisas são atualmente o tipo de saber menos desenvolvido no reservatório de saberes do professor, e também, paradoxalmente, o mais necessário à profissionalização do ensino" (GAUTHIER et al., 2006, p. 34). Ao discorrer sobre as consequências da falta de um saber da ação pedagógica válido, Gauthier et al. (2006) descrevem a situação em que o professor recorre apenas à experiência, à tradição e ao bom senso, ao passo que uma profissão não se caracteriza na ausência da competência com a demarcação de conhecimentos próprios e validados pelo grupo. Assim, o que diferencia o professor dos demais profissionais é o conhecimento específico de ensinar.

O reconhecimento, por parte da população como um todo, de saberes e práticas constituídas por determinado grupo é uma condição para que o processo de profissionalização seja possível. Gauthier et al. (2006, p. 34) defendem que: “[...] para profissionalizar o ensino é essencial identificar saberes da ação pedagógica válidos e levar os outros atores sociais a aceitar a pertinência desses saberes". Ao longo das considerações, os autores ainda demonstram a importância da relação entre as pesquisas sobre a prática docente com os cursos de formação inicial como forma de considerar o valor do saber originado na ação pedagógica.

Em relação aos saberes profissionais específicos da docência, para Gauthier et al. (2006), o processo em que o professor os adquire acontece durante a formação ou em seu trabalho. Esses saberes referem-se, exatamente, às ciências da educação e serão os responsáveis por caracterizar a categoria dos professores, no sentido de ser

[...] um saber profissional específico que não está diretamente relacionado com a ação pedagógica, mas serve de pano de fundo tanto para ele quanto para os outros membros de sua categoria socializados da mesma maneira. Esse tipo de saber permeia a maneira de o professor existir profissionalmente. (GAUTHIER et al., 2006, p. 31).

Práxis Educativa, Ponta Grossa, v. 11, n. 2, p. 505-525, maio/ago. 2016 Disponível em: < http://www.revistas2.uepg.br/index.php/praxiseducativa > 
As profissões possuem saberes próprios e a docência alicerça-se nas ciências da educação para estabelecer os princípios que a caracterizam, de modo a formular o conjunto de saberes sobre a escola. Este, por sua vez, deve ser dominado pelos professores. Conforme salientam Gauthier et al. (2006), tal conjunto de saberes é responsável por diferenciar os professores dos membros de outras profissões.

\section{Os saberes docentes na Educação Infantil a partir das fontes de aprendizagem, dos processos formativos e da prática pedagógica}

$\mathrm{Na}$ presente investigação, discutimos os saberes docentes dos professores da Educação Infantil e, dessa forma, apresentamos as fontes de aprendizagem docente, os processos formativos e a prática pedagógica como elementos da natureza do saber professoral. A necessidade da relação entre a formação específica para a docência e a prática pedagógica fica evidente frente à natureza dos saberes dos professores, por isso elencamos como objeto da presente pesquisa os saberes docentes dos professores da Educação Infantil diante da prática pedagógica.

Para desenvolver a investigação, utilizamos a possibilidade da relação dialética entre o referencial teórico e os dados obtidos a partir dos sujeitos pesquisados. Com as observações ativas, denominação esta a partir dos estudos sobre o grau de participação do observador de Hernández Sampieri et al. (2013), descrevemos episódios da prática das professoras. Posteriormente, realizamos entrevistas semiestruturadas (LÜDKE; ANDRÉ, 1986) com as quatro professoras participantes da pesquisa, mencionadas na investigação como P1, P2, P3 e P4, com a análise de conteúdo na perspectiva de Bardin (2011).

A pesquisa foi realizada em uma instituição pública e duas instituições da rede particular. Duas professoras trabalhavam com turmas do Infantil II, com crianças que completariam dois anos de idade no decorrer do ano letivo, e duas professoras estavam com turmas do Infantil IV, nesse caso, com crianças que completariam quatro anos de idade. Nas instituições da rede particular, encontrávamos turmas de Educação Infantil e dos anos iniciais do Ensino Fundamental, por isso as entrevistas trazem a terminologia escola.

O critério para a escolha das instituições e professoras participantes da investigação levou em consideração a aproximação que estabelecemos com a coordenação pedagógica das instituições e, diante das propostas expostas em reunião inicial, quais professoras aceitaram participar do processo de pesquisa a partir da assinatura do Termo de Consentimento Livre e Esclarecido.

As observações para posterior análise dos episódios aconteceram a partir de uma média de vinte horas, mas tal tempo poderia oscilar levando em consideração a repetição ou não dos episódios em campo de pesquisa. A finalização do processo de observação também ocorreu quando os fatos presentes em sala eram relatados em mais de um episódio. Após esses momentos, propomos as entrevistas, sendo estas efetuadas nas próprias instituições em que as professoras trabalhavam. As entrevistas tiveram a durabilidade de aproximadamente uma hora e meia a duas horas.

Ao investigarmos a constituição do saber professoral, percebemos a complexidade da temática em questão e acreditamos que, para desenvolver os estudos quando questionamos qual a natureza dos saberes docentes, faz-se necessária a compreensão sobre estes diante da especificidade da Educação Infantil. Assim sendo, ao estabelecermos como objetivo deste estudo o fato de desvelar, por meio de interpretações inferenciais, a natureza do saber docente do

Práxis Educativa, Ponta Grossa, v. 11, n. 2, p. 505-525, maio/ago. 2016 Disponível em: <http://www.revistas2.uepg.br/index.php/praxiseducativa > 
professor da Educação Infantil diante da prática pedagógica, foi possível estabelecer as categorias elencadas a seguir, as quais possuem como eixos centrais para as discussões: "as fontes de aprendizagem para dar origem aos saberes dos professores da Educação Infantil”, "o processo de desenvolvimento dos saberes" e "a prática como espaço para a mobilização de tais saberes docentes".

A categoria relacionada às fontes de aprendizagem docente na Educação Infantil foi originada nas demonstrações das professoras participantes da pesquisa, tanto nos episódios observados em sala de aula como nas entrevistas, de que os seus saberes são constituídos a partir de alicerces teóricos e práticos, estando estes presentes na formação específica, no exercício docente e nos aspectos pessoais do professor. Ao depararmo-nos com a relação inseparável dos alicerces citados, elencamos o termo fontes de aprendizagem como pertinente para a discussão da primeira categoria.

Para a elaboração da presente categoria, levamos em consideração o apontamento de Tardif (2002, p. 68) no sentido de que: "O desenvolvimento do saber profissional é associado tanto às suas fontes e lugares de aquisição quanto aos seus momentos e fases de construção". Seguimos a concepção do autor ao associar as fontes e os lugares de aquisição do saber à história de vida dos professores, bem como aos processos formais de formação.

Como momento inicial, a referida categoria traz os dados sobre a importância dos cursos de formação de professores e da atuação na docência, ou seja, os elementos formais como um dos eixos dos processos formativos da docência, enfatizando que é, por meio deles, que os professores adquirem os conhecimentos específicos para o exercício de sua profissão.

Se o professor possui uma boa bagagem de conhecimentos, o profissional terá maiores possibilidades de proporcionar uma aprendizagem satisfatória à criança. A aprendizagem que acontece pela e da partilha entre os sujeitos que convivem no ambiente escolar é qualitativa, mas o professor precisa ter o conhecimento aprofundado para que, no processo de diálogo, seja possível a elevação do nível conceitual do grupo como um todo.

A fim de proporcionar uma aprendizagem capaz de demonstrar-se como significativa para os alunos, o conhecimento do professor é extremamente importante, pois a docência envolve a mediação entre os conteúdos presentes no currículo e a realidade do grupo para o qual o professor ministra as suas aulas. Ao analisarmos o processo de aprendizagem da docência, consideramos que o professor é responsável por estabelecer a conexão entre o desconhecido e o conhecido; assim, seu nível cultural deve ser elevado para gerar a compreensão naquele que está aprendendo. E, a fim de dar fundamentação ao profissional para que realize a medição e possa propor momentos de partilha com seus alunos, apontamos a importância da formação inicial, continuada, em serviço e o conjunto de vivências dos professores ao longo da carreira. Assim sendo, apresentamos a fala de uma das professoras entrevistadas quando questionada sobre a relação entre os cursos de formação e a prática que ela realiza:

A formação continuada eu não tenho dúvida de que precisamos sempre, afinal de contas não somos seres acabados; precisamos estar sempre em formação. Da faculdade também não tem nem o que discutir; a gente precisa, faz parte do nosso trabalho, é a base. (ENTREVISTADA P3).

A P3 identificou a formação inicial como a base para a atuação em sala de aula. Podemos perceber que ela demonstrou seu posicionamento a partir da perspectiva do desenvolvimento profissional docente. Nesse sentido, a continuidade na formação dos professores é vista como um dos pontos chaves para pensarmos em uma prática pedagógica significativa. Desse modo, é fundamental a indissociabilidade entre teoria e prática no processo de tornar-se professor.

Práxis Educativa, Ponta Grossa, v. 11, n. 2, p. 505-525, maio/ago. 2016 Disponível em: < http://www.revistas2.uepg.br/index.php/praxiseducativa > 
Entretanto, em alguns momentos da atuação do professor, pode um lado ou outro ganhar maior destaque, mas a busca do equilíbrio é uma necessidade constante.

Diante da importância do papel da formação docente para a aquisição de conhecimentos referentes à aprendizagem da docência, trazemos o episódio da P1. No desenvolvimento de uma atividade na quadra esportiva da instituição, a pesquisadora acompanhou o encaminhamento da professora à turma, para explorar os sons e os movimentos, por meio dos materiais ofertados. No episódio 1:

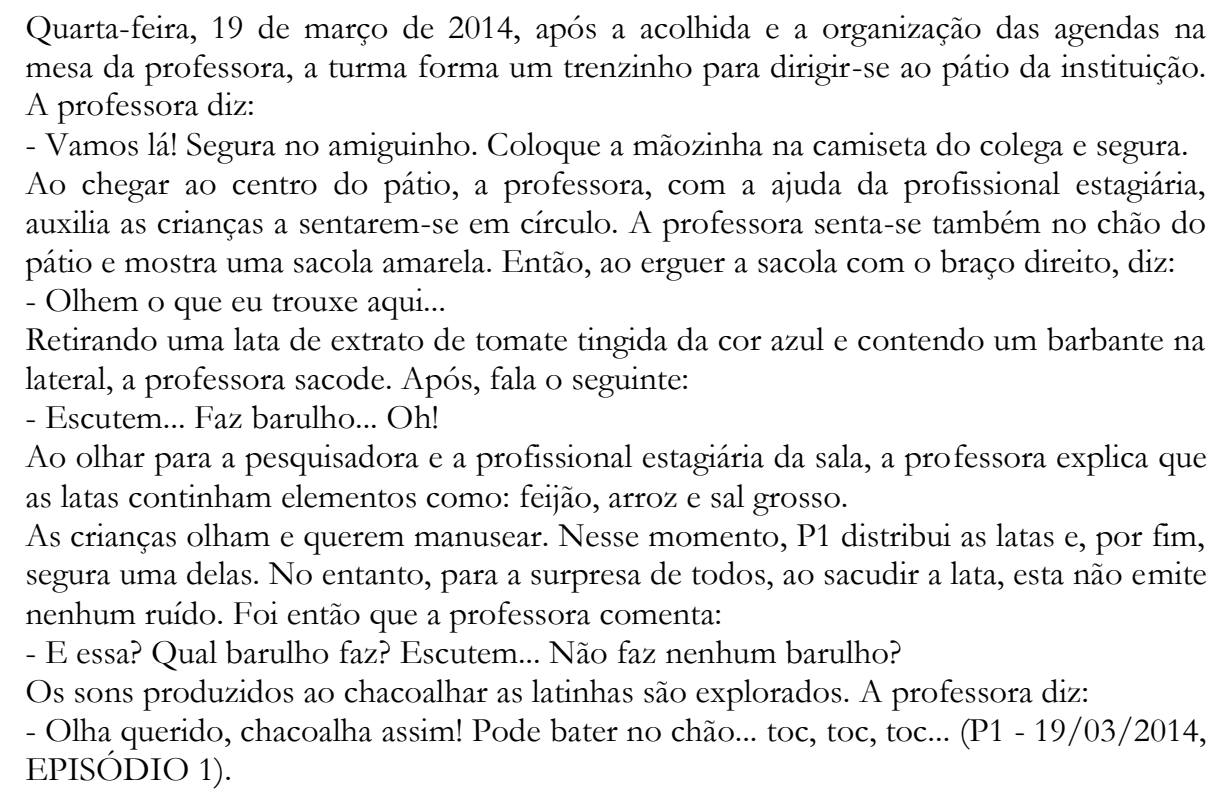

Por meio da análise de tal episódio, verificamos como os conteúdos sobre a socialização, a interação e a afetividade estão presentes na prática pedagógica da Educação Infantil. Durante as observações em sua sala, presenciamos a mediação realizada pela P1 para que as crianças estivessem em constante interação entre elas mesmas, com a profissional estagiária e com a própria professora. Identificamos a importância de a professora ter domínio sobre os conceitos de socialização, interação e afetividade e das metodologias adequadas para trabalhá-los em sala de aula.

Diante disso, podemos inferir a presença de duas fontes de aprendizagem para a origem dos saberes da P1. A primeira pode estar associada às bases científicas mobilizadas pela professora as quais envolvem o conhecimento dos conteúdos e o modo de abordar as temáticas, no caso as cores, as formas geométricas e os sons. A segunda fonte diz respeito ao aprendizado da professora sobre o encaminhamento pedagógico para trabalhar os conceitos científicos. Tal aprendizado deriva dos cursos de formação específicos, mas ressaltamos, também, a importância da prática pedagógica para a origem dos saberes.

A relação entre a formação e a prática docente possibilita a origem, o desenvolvimento e a mobilização dos saberes pelo professor. Não há como desvincular a atuação docente dos cursos de formação e vice-versa. Tardif (2002, p. 41) ressalta: "Os saberes científicos e pedagógicos integrados à formação dos professores precedem e dominam a prática da profissão, mas não provêm dela". Por esse motivo, a formação docente como fonte de aprendizagem oferece bases que auxiliam na compreensão por parte do professor a respeito das especificidades do seu trabalho. 
Assim como as fontes de aprendizagem docente, os processos formativos envolvem a formação inicial, a formação continuada, a formação em serviço e a prática pedagógica, mas em perspectivas distintas. A formação específica para a docência assume o papel de fonte dos saberes e de espaço para os processos formativos. Na condição de fontes de aprendizagem, os cursos de formação oferecem as bases iniciais para a atuação e, como lugares capazes de auxiliar o desenvolvimento dos saberes, os cursos instigam os professores a pesquisarem a prática pedagógica constantemente.

Da mesma forma, situamos condição da prática pedagógica, a princípio, como fonte de aprendizagem para os futuros professores, como, por exemplo, a prática realizada nos estágios e nos programas de inserção à docência. Ao assumir seu espaço para o desenvolvimento do conjunto dos saberes, a prática pedagógica demonstra de modo contínuo as especificidades do processo de ensino aprendizagem e a importância das bases teóricas para fundamentá-las.

Consideramos que os saberes dos professores são temporais; desse modo, são utilizados e desenvolvem-se ao longo da carreira profissional. A socialização dos saberes acontece na carreira do professor, por conseguinte, os profissionais incorporam práticas e rotinas institucionalizadas (TARDIF, 2002). Nesse sentido, elencamos o termo processos formativos para referir-nos à forma como acontece o desenvolvimento dos saberes docentes na carreira do professor da Educação Infantil e constituir a segunda categoria do presente estudo.

A importância da segunda categoria está na condição de que os saberes docentes derivam da relação entre formação e prática. Desse modo, em uma perspectiva de desenvolvimento profissional docente, será importante estudar a relação entre os processos formativos oriundos da formação inicial ou continuada e os oriundos da prática.

De acordo com Vaillant e Marcelo (2012), articular os cursos de formação e as práticas de sala de aula é condição essencial para o desenvolvimento profissional. Além disso, consideramos que formar o docente com base nessa concepção oportuniza a presença do movimento de ida e de volta em relação ao viés teórico e ao viés prático, portanto a ressignificação dos saberes pelo professor. O movimento de ir e de vir com a reflexão do professor para a produção de um saber está presente na fala da P1, conforme é possível acompanhar:

Hoje eu trabalho diferente. Antes eu partia do meu planejamento para a criança; hoje tem o planejamento que eu preciso de um norte, mas hoje eu coloco a criança no meu planejamento e antes não, eu colocava o meu planejamento para a criança. E isso veio com a maturidade profissional, com uma percepção de que, de certa forma, não adianta eu dar um conteúdo simplesmente para cumprir a proposta da escola. (ENTREVISTADA P1).

Pela colocação da P1, identificamos a prática pedagógica como espaço formativo, ao possibilitar o repensar sobre o modo de organizar o planejamento das formas de interação e aprendizagem. A preocupação em tornar a aprendizagem significativa das crianças fez com que a P1 apresentasse outro posicionamento. Agora, a professora considera as particularidades das crianças para organização das aulas e não apenas cumpre o planejamento como uma exigência formal. Inferimos que tal diferença também adveio dos cursos de formação continuada específicos para a docência, porque, ao iniciar a carreira, a professora frequentava o Curso de Licenciatura em Pedagogia e, posteriormente, concluiu dois cursos de Pós-Graduação lato sensu. Portanto, em uma perspectiva de desenvolvimento profissional docente, houve uma relação constante entre a atuação e a formação docente.

A concepção de desenvolvimento profissional inclui os processos de aprendizagem do docente, visto que envolve a continuidade do aprender na constituição dos saberes. Nesse caso, o

Práxis Educativa, Ponta Grossa, v. 11, n. 2, p. 505-525, maio/ago. 2016 Disponível em: < http://www.revistas2.uepg.br/index.php/praxiseducativa > 
Formação de professores e prática pedagógica: uma análise sobre a natureza dos saberes docentes

professor tem como fontes de aprendizagem os cursos de formação, as experiências profissionais e as experiências pessoais, de forma que, com os processos formativos, tanto com viés teórico quanto com viés prático, o professor trabalha para remodelar os saberes da profissão.

A prática pedagógica e a formação profissional apenas como fontes de aprendizagem da docência apresentam caminhos para a constituição dos saberes docentes e interligam-se com a trajetória pré-profissional do professor. Entretanto, os processos formativos necessitam de reflexões por parte do docente ao longo da sua carreira para a reelaboração constante dos saberes. Assim, trazemos o relato de P1 sobre como ela constitui seus saberes:

Então, eu sempre busco mais. Eu busco mais teoria para incrementar a minha prática, para que a minha prática seja melhor. Eu penso que a teoria precisa da prática, como a prática precisa da teoria e uma vai complementando a outra, mais sempre buscando mais. Quanto mais experiência eu tenho, eu necessito de mais conhecimento teórico. (ENTREVISTADA P1).

No discurso da P1, há a articulação entre a prática docente e os saberes profissionais, por isso também acontece a valorização da formação docente. Tal ponto demonstra que o professor relaciona a sua atuação com as abordagens teóricas; logo, não há o distanciamento entre o exercício da profissão e a formação específica, mas um processo constante de ressignificação dos saberes pelo professor.

Da mesma forma, as falas da P4 e da P2 trazem a importância do curso de formação inicial e, paralelamente, o papel da atuação na profissão para a constituição dos saberes. Ao entrevistarmos a $\mathrm{P} 4$, questionamos a professora se a formação inicial interferiu em seu trabalho a partir da elaboração de projetos e sobre a aprendizagem do professor por meio da formação continuada. A P4 respondeu:

Sim, e a gente trabalhava muitos [projetos] nas oficinas na faculdade. Tinha uma semana toda que nós fazíamos as oficinas e é como se fossem os projetos. Acredito que esta experiência foi bem válida.

[...] tem muitos cursos de formação continuada que são excelentes, mas a possibilidade que a gente tem já dificulta tanto financeiramente quanto o tempo. A gente trabalhando em duas escolas ou consegue fazer de cada quinze dias, uma vez por semana, mas são de extrema importância. Vale muito a pena. (ENTREVISTADA P4).

No relato a seguir, a P2 também demonstrou a importância para a aprendizagem docente da relação entre a formação específica com a atuação do professor:

O curso dá base sim para você iniciar, mas como eu falei, você constrói o seu conhecimento e seu aprendizado junto aos seus alunos. (ENTREVISTADA P2).

Foi possível constatarmos que, ao analisar os elementos que interferem na sua atuação, a P4 salientou o papel da formação específica no processo de desenvolvimento dos saberes, realizando a associação da prática em sala de aula com o curso de Licenciatura em Pedagogia e com a formação continuada. Entretanto, ela expôs as dificuldades relativas à participação nos cursos de formação docente no decorrer da carreira.

Já na fala da P2, a valorização da formação também estava presente, mas a professora destacou a relevância da atuação em sala de aula. Esta perspectiva de que, por meio da atuação em sala de aula, o professor reconhece a necessidade da formação para conseguir desenvolver, a partir de conteúdos específicos do currículo e percepções da turma, propostas inovadoras e capazes de valorizar cada sujeito também fica evidente na entrevista com a P1 quando realiza afirmações sobre o trabalho com projetos:

Práxis Educativa, Ponta Grossa, v. 11, n. 2, p. 505-525, maio/ago. 2016 Disponível em: <http://www.revistas2.uepg.br/index.php/praxiseducativa> 
Eu aprendi a trabalhar com projetos e fui aprendendo mais. E agora, assim, eu não tenho tanta dificuldade em elaborar. Dependendo da turma, esse projeto não é assim: vou fazer esse projeto para essa turma e vou continuar esse para outra. Não. Primeiro eu conheço a turma e vejo como que eu posso trabalhar com essa turma. Normalmente, cada turma tem uma característica, tem uma forma de... Uma dinâmica, então eu procuro é... Como eles são pequenos, eles ainda não conseguem definir ainda comigo, então eu percebo, primeiro eu conheço a turma e depois eu percebo as necessidades das crianças, dos conteúdos daquela idade e crio o projeto. (ENTREVISTADA P1).

A reflexão a partir da formação e da atuação docente ficou evidente no relato, assim a P1 destacou a importância de analisar as características da turma para propor o projeto e colocou que esse processo de aprendizagem docente acontece ao longo do tempo. Segundo a professora, a aprendizagem sobre os princípios para a elaboração de um projeto ocorreu inicialmente, sendo o processo de aprender sobre a docência contínuo. A partir da observação criteriosa pela P1 para conhecer as crianças, ela identificou as necessidades do grupo, mobilizando bases científicas e práticas para sua atuação.

Constatamos que os dados da P1 trouxeram aspectos sobre a sala de aula e cada criança que faz parte dela, assim enfatizaram as condições a respeito da natureza individual inseparável da docência ao evidenciar as especificidades das crianças e a coletividade ao destacar a importância do conhecimento da turma. Salientamos que, por um lado, o professor trabalha com os sujeitos de forma individual e, concomitantemente, trabalha com um grupo, ou seja, com a coletividade.

Da forma como Tardif e Lessard (2005) assinalam, devido à natureza individual e ao mesmo tempo social do objeto do trabalho docente, há a necessidade de conciliar os componentes relacionais individuais e coletivos. A docência apresenta-se permeada pela igualdade de tratamento entre os alunos pelo professor, considerando a ética profissional, e, por outro lado, as necessidades de cada aluno com suas expectativas particulares atravessam-na. Com isso, evidencia-se uma condição ambígua da docência, segundo a qual o professor tem de conhecer a turma como um todo e os seus alunos de forma particular para conseguir trabalhar com as diferenças dos sujeitos na prática em que realiza.

Assim sendo, ao realizarmos este estudo, ainda encontramos uma terceira categoria e, para ela, utilizamos como alicerce os estudos de Gimeno Sacristán (1999) a fim de problematizar a prática como ambiente em que o professor mobiliza seus saberes e também a prática como espaço de contato com a cultura compartilhada por um grupo, no caso a cultura partilhada pelos profissionais da educação. Nesse sentido, a prática comporta o diálogo entre a cultura subjetiva e a cultura objetiva do professor (GIMENO SACRISTÁN, 1999).

Por isso, ao mesmo tempo que o professor enriquece a prática do grupo com as suas ações, também a utiliza como fonte. Ambas as condições estiveram presentes ao longo da pesquisa, pois as professoras questionaram a prática presente nas escolas para enriquecê-la e utilizaram-se dela como cultura de saber fazer para encaminhar as aulas. As falas da P1 e da P2 confirmaram a relação entre a prática que já faz parte da instituição e a influência do próprio professor nessa cultura objetiva:

Então, na verdade, eu sigo a Proposta e acrescento dentro do que eu acredito. Assim, eu sigo a Proposta Pedagógica da escola e acrescento. Eu tenho respaldo da escola, então, não teve nenhuma ocasião em que determinada coisa não se pudesse fazer. Claro que eu tenho o bom senso de seguir a proposta da escola, mas posso, tenho a liberdade de trazer novidades nas atividades para a realização. (ENTREVISTADA P1).

Práxis Educativa, Ponta Grossa, v. 11, n. 2, p. 505-525, maio/ago. 2016 Disponível em: <http://www.revistas2.uepg.br/index.php/praxiseducativa > 
A partir do Projeto Político Pedagógico da escola é que você vai direcionar os seus conteúdos para os alunos, claro que adaptando para cada faixa etária, para cada aluno, vendo as diversidades, mas ele está diariamente ali junto. (ENTREVISTADA P2).

Nas falas da P1 e da P2, identificamos um núcleo rígido proveniente, da forma como denomina Gimeno Sacristán (1999), de práticas educativas consolidadas pelos processos de estruturação institucionalizada por meio do habitus. A consolidação de rotinas, da estrutura do trabalho docente, da organização escolar, é importante desde que não se coloque a incapacidade ao professor em interferir nelas. No caso dos relatos anteriores, ficou-nos notória a influência das professoras pela Proposta Pedagógica da escola e vice-versa. Quando a P1 citou que segue a Proposta Pedagógica, situou-a na condição de prática institucionalizada. Por outro lado, a capacidade de criar, de flexibilizar, de reorganizar as atividades para a aula faz com que a prática se apresente como

[...] sinal cultural de saber fazer composto de formas de saber como, ainda que ligado também a crenças, a motivos e a valores coletivos, afirmados e objetivados com marca impessoal. Essa marca é cultura intersubjetiva e objetiva, é expressa em ritos, costumes, sabedoria compartilhada, instituições, espaços construídos para educar, formas de vida dentro de organizações escolares, estilos de fazer em contextos sociais e históricos, orientações básicas e papeis estáveis. Alunos, pais e professores, especialis tas e políticos encontram essa marca como condição prévia à ação. (GIMENO SACRISTÁN, 1999, p. 74).

A prática composta pelos elementos da cultura de um grupo não está ausente de elementos pessoais, porque funciona como fonte da ação e essa mesma ação poderá enriquecê-la. Nessa condição, as marcas pessoais e culturais estão presentes ao analisarmos a prática educativa. Embasamo-nos, assim, em Gimeno Sacristán (1999), que define a prática educativa como algo real no funcionamento atual das instituições e, também, como conhecimento elaborado. Exatamente a via de mão dupla entre a interferência das práticas institucionalizadas e as advindas de cada sujeito apareceu quando a P1 e a P2 preocupam-se em realizar adaptações a partir do que aparece descrito em um dos documentos da instituição, pois a prática deixou de estar completamente codificada, demonstrando-se possível de alterações.

A capacidade que o professor tem de modificar a prática existente também esteve presente na fala da P4 sobre a relação entre o currículo e o seu planejamento diário. A fala em questão reforçou o fato de que o professor se nutre de uma prática coletiva e institucionalizada, mas é capaz de agregar elementos a ela:

Cada planejamento é de acordo com a turma. Se eu faço o planejamento com aqueles conteúdos e a minha turma não acompanha, como que eu vou colocar se a minha turma não conseguiu atingir. A gente consegue fazer a partir da turma e não só para ter no papel. O planejamento é uma regra, mas a regra precisa estar conforme as crianças. Não adianta a gente encher de coisas sendo que eles não irão conseguir atingir na prática. (ENTREVISTADA P4).

Quando a P4 citou que o planejamento é uma regra, situou-o na condição de prática institucionalizada. No entanto, ao ressaltar a necessidade de adaptá-lo segundo a realidade da turma, a professora perpassou pela definição de prática expressa por Gimeno Sacristán (1999). Nesse sentido:

A prática não é, ou não é somente, uma técnica derivada de um conhecimento sobre uma forma de fazer; não é só o exercício e a expressão de destrezas individuais, nem se circunscreve, exclusivamente, às salas de aula; ela vai além das ações dos professores e dos estudantes. (GIMENO SACRISTÁN, 1999, p. 95).

Práxis Educativa, Ponta Grossa, v. 11, n. 2, p. 505-525, maio/ago. 2016 Disponível em: <http://www.revistas2.uepg.br/index.php/praxiseducativa> 
Como a prática ultrapassa a técnica do fazer, o encaminhamento das aulas vai além do ato de planejar atividades a serem cumpridas pelos alunos a partir da descrição dos conteúdos presentes no currículo da turma. Assim, as professoras pesquisadas planejavam as propostas para as aulas e, por outro lado, realizavam adaptações devido às situações reais de ensino.

Nesse sentido, ao mobilizar saberes, o professor interfere na prática e esta interfere na constituição do seu reservatório de saberes. Assim, destacamos o relato da P1 em relação à forma como foi aprendendo a organizar a aula por meio do trabalho fundamentado na atitude reflexiva sobre a prática pedagógica:

Às vezes, eu programava uma atividade e não tinha noção de quanto tempo ela iria
durar. Eu imaginava, então, me batia com a organização do tempo. Hoje, eu sei que
determinada atividade, ela tem, aproximadamente, um período de duração. A gente já
faz uma margem a mais. Mas no começo, não. Eu começava, às vezes, a aplicar uma
atividade e já estava na hora do lanche. Eu tinha que parar. Não digo que isso, às vezes,
não pode acontecer hoje, mas hoje eu sei lidar com a situação e na época eu ficava
muito preocupada. Eu não estava conseguindo apresentar o conteúdo para as crianças
de maneira organizada, então, isso eu fui aprendendo, desenvolvendo durante o tempo
de trabalho. (ENTREVISTADA P1).

Quando a P1 salientou desenvolver a percepção da distribuição do tempo nas formas de interação e aprendizagem pela experiência nos anos de trabalho na docência, concedeu maior relevância aos saberes experienciais. Entretanto, apesar de a professora citar o fator experiência na docência como influente para a organização dos tempos e dos espaços, ela ressaltou que, ao longo dos anos de exercício da profissão, ainda se depara com a necessidade de reorganizar as atividades devido à imprevisibilidade da profissão. Nesse sentido, houve o processo de reflexão crítica realizado pela $\mathrm{P} 1$, conferindo o status de incompletude da aprendizagem docente. $\mathrm{O}$ processo reflexivo oportuniza o reconhecimento da importância sobre a aprendizagem da docência acontecer de modo permanente.

Além dos saberes experienciais, a P1 atribuiu a percepção do tempo na proposta de atividades também à formação específica. Quando indagada sobre quais fatores influem na organização do tempo, a P1 demonstrou o seguinte posicionamento:

Seria à experiência? Eu preciso da teoria? Sim! Lá na escola, eu sei como eu vou trabalhar. A teoria me diz, me auxilia como eu posso trabalhar, o que eu estou trabalhando com a criança em determinada atividade, mas na hora de aplicar, a experiência contou de certa forma mais do que a teoria. (ENTREVISTADA P1).

Nesse viés da relação teórico prática, a P3 citou a influência da observação das práticas das outras professoras e, posteriormente, relatou sobre os estágios, sendo estes componentes da formação inicial. Ao ser questionada a respeito do que a auxiliou na constituição da concepção sobre a organização dos materiais em sala, a professora relatou:

Eu acredito que mais a observação. A disposição dos materiais, eu observo bastante. Eu procuro aprender em cada lugar. Nos meus estágios eu procurei sempre estar aprendendo, observando e sempre criando alguma coisa diferente. (ENTREVISTADA P3).

A P1 atribuiu importância à teoria e estabeleceu destaque para o saber experiencial ao realizar as adaptações nas atividades propostas. Quando o relato da P3 destacou o papel da observação para o seu atuar em sala, trouxe os saberes desenvolvidos na prática de sua profissão ou saberes experienciais, mas, ao citar os estágios, também ressaltou os saberes da formação profissional. No processo de entrevista, a P1 e a P3 citaram o cotidiano, problematizado por Heller (1985), e as bases teóricas como fatores capazes de auxiliar na organização dos tempos e

Práxis Educativa, Ponta Grossa, v. 11, n. 2, p. 505-525, maio/ago. 2016 Disponível em: <http://www.revistas2.uepg.br/index.php/praxiseducativa> 
dos espaços; todavia, os professores identificam com maior facilidade os saberes provenientes da experiência. É importante destacar que os saberes experienciais, além do conhecimento empírico, mantêm vínculos com as concepções de ensino dos professores e não estão dissociados das bases teóricas da docência.

\section{Considerações finais}

Destacamos que a prática pedagógica comporta ações concretas, mas, se estas estiverem dissociadas da reflexão crítica a partir da formação específica para a docência, tal prática não será capaz de emancipar os sujeitos. Assim, o presente estudo a respeito dos saberes do professor preocupou-se em destacar quais fontes possibilitam a existência do saber professoral; logo, incluiu a formação dos professores e as experiências pessoais também, além das experiências do exercício docente, sendo a relação entre os três referentes citados a responsável por caracterizar os saberes docentes como heterogêneos.

Ao evidenciarmos a importância do exercício da docência para a constituição dos saberes do professor, ressaltamos que a formação profissional não pode estar dissociada da análise sobre o papel da prática pedagógica. O exercício da docência demanda a formação específica do professor; por isso, de modo algum, colocamos em uma espécie de hierarquia o papel dos cursos de formação e do atuar na docência. Por tal razão, enfatizamos a necessidade constante da relação entre o viés teórico e o viés prático para que o professor atribua sentidos aos conceitos e às ações de modo a formular o seu conjunto de saberes, denominado "reservatório de saberes".

Como contribuições deste estudo, colocamos a consideração referente ao papel da prática para além das certezas acumuladas de forma individual; logo, a partir da reflexão crítica em relação aos saberes experienciais, a prática também possibilita uma determinada objetivação desses saberes. Salientamos que a subjetividade é uma das características marcantes dos saberes experienciais, mas, além dela, a objetividade faz-se presente pelo processo de interação, por meio da experiência coletiva. Nessa direção, as professoras contemplaram, em suas entrevistas, a importância da partilha entre os colegas de profissão e da relação com os alunos na constituição e na reelaboração dos saberes docentes.

Assim, desvelar a natureza dos saberes docentes é um meio de ampliar o entendimento sobre a complexidade das ações desenvolvidas na sala de aula, de modo a perceber a prática pedagógica como aquela que ultrapassa o ato de desempenhar um conjunto de ações técnicas e dissociadas. A prática pedagógica é tão ampla a ponto de associar-se a outras fontes para dar fundamentos aos saberes docentes, possibilitar que estes sejam repensados e reelaborados diante dela e, em uma condição dialética, a modifiquem também.

Ao questionarmo-nos sobre a natureza dos saberes docentes do professor da Educação Infantil diante da prática pedagógica, concluímos que o conjunto de saberes advém da formação específica na perspectiva do desenvolvimento profissional docente e, sincronicamente, os saberes docentes também carregam marcas das experiências profissionais e pessoais. Ao tomarmos a formação e a atuação como elementos responsáveis por oferecer a especificidade da docência, identificamos a necessidade de aprofundar nossas análises sobre os processos formativos dos profissionais e reconhecemos que os saberes docentes são complexos, constituídos pelos professores desde o momento em que estavam na condição de alunos; posteriormente, adquirem características provenientes da formação inicial e continuada. Nesse sentido, o processo de desenvolvimento perante a prática pedagógica também é constante.

Práxis Educativa, Ponta Grossa, v. 11, n. 2, p. 505-525, maio/ago. 2016 Disponível em: <http://www.revistas2.uepg.br/index.php/praxiseducativa > 
Diante dos resultados, podemos concluir que, apesar de acompanharmos nos episódios a mobilização dos saberes da formação profissional pelas professoras participantes da pesquisa, o tempo escasso para a formação continuada foi um ponto levantado nas entrevistas. Em poucos momentos, as entrevistadas relataram sobre os encaminhamentos da formação em serviço, o que denota uma das fragilidades a serem superadas para trabalharmos a formação a partir do desenvolvimento profissional docente.

Com os resultados e os argumentos apresentados, entendemos que os saberes dos professores precisam ser valorizados ao longo do processo de formação docente. No entanto, a palavra "saberes" não abrange apenas as experiências do professor, mas também o conhecimento que ele possui sobre os conteúdos e como ensiná-los. Esses saberes, a princípio adquiridos no curso de formação inicial, estão sempre em processo de constituição e dependem de momentos de reflexão crítica, no caso propostos na formação contínua e em serviço relacionadas à prática pedagógica. Assim, a atuação impulsiona o docente para buscar saberes das ciências da educação diante de situações do cotidiano escolar e, ao mesmo tempo, tem o caráter de nutrir o reservatório de conhecimentos do professor.

\section{Referências}

BARDIN, L. Análise de conteúdo. São Paulo: Edições 70, 2011.

GAUTHIER, C. et al. Por uma teoria da pedagogia: pesquisas contemporâneas sobre o saber docente. 2. ed. Ijuí: Unijuí, 2006.

GIMENO SACRISTÁN, J. Poderes instáveis em educação. Porto Alegre: Artes Médicas Sul, 1999.

HELLER, A. O cotidiano e a história. 2. ed. Rio de Janeiro: Paz e Terra, 1985.

HERNÁNDEZ SAMPIERI, R. et al. Metodologia da pesquisa. 5. ed. Porto Alegre: Penso, 2013.

LÜDKE, M.; ANDRÉ, M. E. D. A. Pesquisa em educação: abordagens qualitativas. São Paulo: EPU, 1986.

NÓVOA, A. Formação de professores e profissão docente. In: NÓVOA, A. (Org.). Os professores e a sua formação. Lisboa: Dom Quixote, 1992. p. 13-33.

SILVA, M. Complexidade da formação de profissionais: saberes teóricos e saberes práticos. São Paulo: Cultura Acadêmica, 2009.

TARDIF, M. Saberes docentes e formação profissional. Petrópolis: Vozes, 2002.

TARDIF, M.; LESSARD, C. O trabalho docente: elementos para uma teoria da docência como profissão de interações humanas. Petrópolis: Vozes, 2005.

THERRIEN, J.; LOIOLA, F. A. Experiência e competência no ensino: pistas de reflexões sobre a natureza do saber-ensinar na perspectiva da ergonomia do trabalho docente. Educação \& Sociedade, Campinas, n. 74, p. 143-160, abr. 2001. DOI: 10.1590/S0101-73302001000100009 
Formação de professores e prática pedagógica: uma análise sobre a natureza dos saberes docentes

VAILLANT, D.; MARCELO, C. Ensinando a ensinar: as quatro etapas de uma aprendizagem. Curitiba: UTFPR, 2012.

Recebido em 02/03/2016

Versão corrigida recebida em 25/04/2016

Aceito em 30/04/2016 